\title{
Indigenous Evaluation in the Northwest Territories: Opportunities and Challenges
}

\author{
Debbie DeLancey \\ Hotì ts'eeda: NWT SPOR SUPPORT Unit
}

\begin{abstract}
There is increasing interest by governments and other service providers in the potential for Indigenous evaluation methods and approaches to support the evaluation of programs and services in a way that is culturally appropriate and responsive. Indigenous governments and organizations are using Indigenous evaluation methods and approaches to inform their own program and service delivery. This article explores the current status of Indigenous evaluation in the Northwest Territories, the opportunities for expanding the use of Indigenous evaluation, and some of the challenges that must be addressed.
\end{abstract}

Keywords: Canada's north, co-creation, culturally responsive evaluation, Indigenous evaluation, NWT Evaluation Symposium, self-government

Résumé : Les gouvernements et autres fournisseurs de services accordent de plus en plus d'intérêt aux méthodes et approches autochtones en matière d'évaluation, afin de mieux appuyer lévaluation de programmes et de services de manière respectueuse et adaptée à la culture autochtone. Les gouvernements et les organisations autochtones utilisent des approches et des méthodes autochtones en matière dévaluation pour éclairer leurs décisions concernant les programmes et services pour lesquels ils sont responsables. L'article explore létat actuel de l'évaluation autochtone dans les Territoires du Nord-Ouest, les possibilités d'élargissement de l'usage de lévaluation autochtone et certains des défis qui doivent toujours être relevés.

Mots clé : Nord du Canada, cocréation, évaluation adaptée à la culture, évaluation autochtone, symposium dévaluation des TNO, autonomie gouvernementale

There appears to be a revitalized interest in evaluation across northern Canada, with a focus on Indigenous evaluation. Participation in the 2018 NWT Evaluation Symposium, the recent re-establishment of a Yukon Chapter of the Canadian Evaluation Society, and the recent Request for Proposals issued by Inuit Tapiriit Kanatami for the development of a five-year Monitoring, Evaluation and Learning Plan, all point to this renewed focus (Inuit Tapiriit Kanatami, 2019). In the Northwest Territories (NWT), this interest is manifesting itself in the context of a seismic shift in the shape of governance in the NWT and an emerging interest in the role that Indigenous evaluation may play in this new landscape. Specifically, the

Corresponding Author: Debbie DeLancey, D. J. DeLancey Consulting, 117 Moyle Drive, \#6, Yellowknife, NT, X1A 0B6; ddelancey33@gmail.com 
introduction of Indigenous evaluation approaches has great potential to advance the field of evaluation and contribute to the utilization of evaluation findings in policymaking in the NWT and across northern Canada.

In this paper I present the historical context of evaluation in the NWT and explore the potential for Indigenous evaluation to make a major contribution to the current and emerging governance of public and Indigenous programs in the territory. I consider the challenges to full utilization and implementation of Indigenous evaluation and propose opportunities to address those challenges in the context of current policy and program initiatives.

I am not an expert on Indigenous evaluation, nor can I ever become one. I am a settler who has made the NWT my home since the 1970s, generously welcomed as a resident during this time on the traditional territory of Chief Drygeese, the home of the Yellowknives Dene First Nation, in Yellowknife; in the community of Radeli Ko'e (Fort Good Hope), home of the Kasho Got'ine; and in Baker Lake and Iqaluit in what is now Nunavut. The perspective I offer in this article is that of a non-Indigenous evaluator who is a long-term resident of the NWT with a career that spans more than 40 years of working with Indigenous organizations and the Government of the Northwest Territories (GNWT). During that time, I have had the privilege of working for and with a number of Indigenous organizations and communities, and collaborating with Indigenous colleagues and Elders on research related to socio-economic assessment of resource development projects, community-based research, documentation of traditional knowledge, community development, and issues related to health and well-being. Any insights that I have developed about the co-creation of research approaches and the potential for Indigenous evaluation to inform public discourse in the North I owe to the wisdom and patience of those Indigenous colleagues who taught me more about other ways of knowing, other research methods, and other modes of knowledge translation than what I brought with me from my training as a social scientist.

Some of the information and many of the insights contained in this article, particularly those dealing with the history of evaluation in the NWT, have been gleaned from my role as a practitioner in the NWT and from discussions with people in public and Indigenous governments and non-government organizations, as there is relatively little published information available.

\section{THE EMERGING GOVERNANCE LANDSCAPE IN THE NORTHWEST TERRITORIES}

Occupying a land mass of 1.346 million square kilometres, the NWT has a population of just under 45,000 residents, of whom approximately 50\% are Indigenous (First Nations, Inuvialuit, or Métis) (Statistics Canada, 2017). This dispersion of a small population over a large territory with limited transportation infrastructure creates governance challenges in and of itself, but governance in the NWT is made more complex because it is continually evolving as Indigenous 
governing organizations (IGOs) negotiate and finalize agreements dealing with lands, resources, and self-government. At the time of writing, twelve IGOs had completed, or were currently engaged in, negotiation of land claims agreements (three completed), land claims and self-government agreements (one completed), self-government agreements (one completed, six in negotiations), and/or land, resources, and self-government agreements (three in negotiations). An additional three communities are seeking governing powers at a community level, unique to the interests of their membership (GNWT, n.d. b). Each of these agreements provides the IGO with some degree of jurisdiction and authority over a broad range of governance areas, typically including management of land, water, renewable resources and harvesting, heritage, education, and a range of social programs.

The GNWT is a public government with province-like powers. But as Indigenous governments complete self-government agreements, jurisdiction over many of the powers and duties of a provincial-style government is available to be drawn down by Indigenous governments. There is no common template for how this will happen, or for what mechanisms may be put in place to provide for shared jurisdiction in areas of common interest. Further, since NWT land claims and self-government agreements have been completed over a period of many years (beginning with the signing of the Inuvialuit Final Agreement in 1984), the scope of topics and level of detail included in those agreements have evolved as the focus has broadened from dealing only with land rights, to the broader range of self-governing authorities outlined above.

At the community level, GNWT legislation provides for the creation of charter communities, which allow Chiefs and Councils to assume the role of a municipal corporation, thereby expanding their authority to include all aspects of municipal-type government responsibility, ranging for example from operation of water treatment facilities to provision of sport and recreation programs.

The result is a continually changing, and potentially confusing, governance environment where many government programs and services will be delivered differently in different regions of the NWT. Some possible scenarios for how this might evolve include the following:

- $\quad$ some programs remain under GNWT jurisdiction and will be delivered by GNWT, for example, health (with the exception of traditional healing), but with the potential for regionally differing delivery mechanisms to be negotiated;

- Indigenous governments will draw down jurisdiction for some programs as provided for in self-government agreements and become fully responsible for designing and delivering those programs, for example, early childhood education, resulting in different approaches among regions;

- Indigenous governments may choose not to draw down jurisdiction in the near future, in which cases GNWT may continue to deliver programs through a contractual arrangement, such as the Tł̣chǫ Intergovernmental Services Agreement (Tł̨chǫ Government, 2003); 
- Indigenous governments may draw down jurisdiction in areas where their authority within self-government agreements has been limited, for example, in the Délînê Final Self-Government Agreement, jurisdiction with respect to kindergarten to Grade 12 education of students must be exercised within a curriculum framework and graduation requirements established by the GNWT (Délînê Got'ine Government, 2013).

Given the nature of rights negotiations between Indigenous nations and Canada, it is evident that governance in NWT will be in a state of evolution for years to come. Further, if the GNWT acts on the newly stated priority of the $19^{\text {th }}$ Legislative Assembly to implement UNDRIP, this may result in changes to current GNWT negotiating mandates and broaden the scope of future self-government agreements (Legislative Assembly of NWT, 2019). This presents a number of challenges for the systematic use of evaluation to provide insights into the delivery of government programs and services. With respect to the role of the GNWT, each of the scenarios outlined above will require a different evaluation approach depending on the extent of GNWT authority and involvement and the development of appropriate methods, thus potentially requiring a larger investment in evaluative activity to support the disparate needs. For Indigenous governments, there will be a need to build evaluation capacity. All parties will be challenged to find common ground in establishing theories of change and shared outcomes for territorial programs that are delivered differently among regions, and they will need to find ways to collaborate to determine what policies and guidelines will be applied, to reach common agreement on what methods and approaches are appropriate and effective in each governance context outlined above, and to identify the parties best suited to commission and implement evaluation in each setting.

\section{THE NWT EVALUATION CONTEXT}

The evaluation function in the GNWT was formally established in 1995, when a program design and evaluation unit was established within the Financial Management Board Secretariat (now the Department of Finance). Over time, this function has been combined with the budgeting function in Finance, or housed within the Department of Executive, but the fundamental mandate to promote evaluation within GNWT has remained unchanged. The unit has produced a series of manuals, guides, and workbooks to support program design and evaluation activities within the GNWT (GNWT, 2014). They also provide training, ranging from short workshops to offering support for GNWT employees to engage in graduate-level coursework. Although the evaluation resources are publicly available, outreach beyond GNWT employees has not been a major focus of the unit's mandate.

There was a stand-alone NWT Chapter of the Canadian Evaluation Society (CES) for many years, but in the early 2000s the local capacity to maintain a separate chapter was deemed insufficient, and NWT joined the Alberta Chapter 
of CES. Although some efforts were made to reach out to the non-government sector and Indigenous organizations, membership was composed primarily of federal and GNWT employees, and a few private-sector consultants, mostly resident in Yellowknife.

\section{Historic challenges to Indigenous evaluation in NWT}

Until recently, the promotion and utilization of evaluation have generally not been a priority of Indigenous governing organizations in the NWT. As has been noted by many authors in Canada and elsewhere, Indigenous communities and organizations have developed a deep distrust of research, including evaluation, as a result of a history of extractive research (Gaudry, 2015; National Collaborating Centre for Aboriginal Health, 2013). Larry Bremner noted in a keynote reflection at the NWT Evaluation Symposium in May 2018 that evaluators "have stolen their knowledge, we've taken their stories and we haven't returned anything of benefit."

This distrust and skepticism about the usefulness of research and evaluation have been made worse by the language of evaluation. Terms like "logic model" and "indicator" are not generally meaningful for people who are untrained in evaluation and research methods, and they may seem even more alienating to people whose first language is not English (DeLancey, Radu, Enosse, \& Ritchie, 2018; Waapalaneexkweew, 2018).

When evaluation has been initiated by Indigenous organizations, it has frequently been in response to a requirement from a funding agency-most often a territorial or federal government agency-rather than as an internally driven initiative to drive program or service improvement. This is consistent with the experience of other Indigenous groups in North America (Martinez, Running Wolf, BigFoot, Randall, \& Villegas, 2018).

Compounding this historic distrust and skepticism about the value of evaluation is a lack of time and resources. Indigenous governing organizations in NWT have, for the most part, been focused on one overriding priority, which is the negotiation and implementation of land claims, resources, and self-government agreements, an activity that is all-consuming and takes many years to complete. Smaller organizations, such as band councils and Indigenous non-profit groups, face capacity and capability challenges including limited funding, lack of sustained funding for most programs, and difficulties in recruiting and retaining qualified staff-all of which mean that resources and attention tend to be focused on the immediate pressures of program delivery rather than other components of the program cycle (i.e., planning, monitoring, evaluation, and continuous improvement based on evidence).

\section{Contemporary challenges}

The concept of Indigenous evaluation provides an opportunity to change the narrative of evaluation as a tool of colonization, as something that is imposed on Indigenous governments and organizations by external agencies and not relevant to their own needs and priorities (Bowman, Francis, \& Tyndall, 2015). But this is 
a relatively new field, and there are barriers to utilization-including a shortage of trained Indigenous evaluators in Canada and the absence of formal learning opportunities for Indigenous evaluation in a Canadian context.

Another challenge is that Indigenous evaluation approaches and methods may not be understood by public governments and funding agencies to be as rigorous, credible, or valid as those with which they are more familiar. The beliefs and values that inform Indigenous evaluation approaches, which are grounded in Indigenous ontologies and epistemologies and defined by Indigenous communities, may not resonate with funders (Gregory, Easterling, Kaechele, \& Trousdale, 2016). The greater emphasis on qualitative methods and reliance on stories and Elders' wisdom which is characteristic of Indigenous approaches may be seen as less rigorous. Kawakami, Aton, Cram, Lai, and Porima (2007) note that Indigenous nations and communities are not homogeneous and that effective methodologies must be rooted in local knowledge and traditions. Kovach (2009) also stresses that Indigenous knowledge cannot be standardized but must be contextualized. Although this need for differing approaches and methods appropriate to local circumstance is not substantially different from the accepted use of a variety of approaches and methods in the established western evaluation profession and tradition, the fact that Indigenous evaluations differ in format and approach may pose an impediment to acceptance and understanding on the part of funding governments and agencies with respect to the contribution that these evaluation products make to fit with their needs.

To date, the use of evaluation as a program improvement tool has not systematically been embraced or adopted by Indigenous governments and organizations in the NWT. The outcomes and measures promoted by evaluation professionals often do not reflect the values and priorities of Indigenous governments and organizations (Kawakami et al., 2007). Indigenous communities and governments are frustrated by what they perceive as an unnecessary need to demonstrate outcomes of community-driven projects and programs to the dominant society, particularly those that are rooted in values that are deeply grounded and universally shared. As former Chief Roy Fabien of the Katlodeechee First Nation described it, "We're trying to justify ourselves as Dene people, here. We don't need to .... To me, this is a colonization process we're in right now .... The whole process-is it about money? If we toe the line and do everything that they tell us to, then we get money?" (CBC North, 2017).

\section{A GROWING INTEREST IN EVALUATION}

The GNWT and, to a lesser extent, municipal and community governments and some NWT non-government organizations have regularly utilized evaluation studies to inform the design, development, and improvement of programs and projects in the NWT, but as noted above, until recently there appears to have been less interest on the part of Indigenous governments and organizations. Recent events described below indicate that this is changing, and they point to an 
emerging interest in evaluation as a means for Indigenous governing organizations to ensure that the programs and services they are providing to beneficiaries and residents are effective, and as a means of accountability to beneficiaries and not just to external funders.

\section{Evaluation as a means of demonstrating outcomes: On-the-land programs}

Indigenous governing organizations and communities have long been subjected to requirements for reporting on activities and outcomes imposed by funding agencies, and the requirement has been experienced as an imposition with little relevance to local needs and priorities (GNWT, 2001). However, there is also recognition that undertaking sound evaluation practices can be an essential step in accessing continued funding from external agencies, both governmental and non-governmental. One area where this recognition has recently gained traction is that of land-based programming. On-the-land programs play an important role in Indigenous communities, providing a range of benefits that include connection to language and culture, transmission of traditional knowledge and values, healing opportunities, and many more (Burgess, Mileran, \& Bailies, 2008; Burgess et al., 2009; Redvers, 2016; Wildcat, McDonald, Irlbacher-Fox, \& Coulthard, 2014). Land-based programming is expensive, including costs of transportation, infrastructure, staffing, and insurance, among others (Wildcat et al., 2014) The programming costs mean that Indigenous communities are continually seeking funding to support what is seen as a critical need in their communities.

To help communities address this need, the NWT On The Land Collaborative (OTLC) was established in 2015 by TIDES Canada and the GNWT to provide NWT organizations and communities with one-window access to funding, and to lever additional funding. The OTLC is composed of government (territorial and Indigenous), charitable, corporate, and not-for-profit partners, and in 2018 it distributed $\$ 1$ million in funding to 48 land-based projects in NWT.

Funders of land-based programming often see the investment as an opportunity to achieve broad social outcomes-land-based programs often have stated goals that include healing, addictions treatment, reduction in youth crime, language enhancement, to name a few. Funders and program sponsors want to see evidence that the intended outcomes are being achieved, or at least that there is a direct link between program activities and the intended results. But often, land-based programs are focusing on issues whose origins are rooted in a multigenerational shared community experience of colonization, residential school, dispossession of lands, and institutional racism, and the impacts of programs will not be realized in the short term (Bowman et al., 2015, Williams, 2018). Generally, these programs are short-term due to financial and other constraints, lasting from just a few days to a few weeks, which only increases the difficulty of achieving substantial impacts in response to generational issues.

Further, there is skepticism in Indigenous communities about the need to evaluate an activity that is universally understood to have inherent value. As one 
leader noted, "You can't evaluate land-based programs. That's ridiculous. We all know what it feels like when you get out of town and you get on the land. How do you measure that?" (DeLancey et al., 2018). At a 2017 Pan-Territorial On The Land Symposium held in Yellowknife, a panel discussion on evaluation approaches for land-based programs prompted a heated exchange that illustrated how deeply rooted is the distrust of evaluation activity in this area. Iona Radu summarized this divide by distinguishing between how evaluation of land-based programs has been perceived as "judging the merit, worth and significance of a program" to see if it measures up to standards set by external funders; and the use of evaluation as a tool for "coming to know," that is, making new knowledge to guide programming in a good way (DeLancey et al., 2018).

OTLC partners and funding recipients have worked together to bridge this gap. In 2019, the OTLC convened a gathering of land-based program funders, practitioners, and evaluators with interest and experience in working with these programs, to begin the process of developing a shared understanding of approaches to evaluating on-the-land programs. Organizers hoped that this work could lead to a body of literature that would propose a generally accepted program theory for Indigenous land-based programming, and shared best practices that would be grounded in Indigenous epistemology, while also being accepted as credible by funders and program sponsors. Participants concluded that there is value in developing a shared theory of change to help program funders understand the link between short-term outcomes and longer-term outcomes. They proposed further work to engage the broader community of organizations working in this field to collaborate on developing best practices in evaluation approaches and methods for land-based programming, on the assumption that this collaboration on a large scale would support general acceptance of these methods and approaches by funders (Tides Canada, Sahtu Renewable Resources Board, NWT Recreation \& Parks Association, \& GNWT, 2018).

\section{Evaluation for self-government: The NWT Evaluation Symposium}

In the context of the evolving governance landscape in the NWT described above, Indigenous governments are increasingly engaged in delivering programs and services to beneficiaries and other residents in their areas of jurisdiction, and in generally establishing themselves as governments exercising the full range of powers and duties that fall within their purview.

In 2018, the Alberta and NWT Chapter of the CES partnered with Dedats'eetsaa: the Tłıchǫ Research \& Training Institute of the Tłıchǫ Government, to host the NWT Evaluation Symposium in Yellowknife. The Symposium was organized as an ancillary event following the CES Annual Conference, which was also hosted by the Alberta and NWT Chapter, and was held in Calgary, Alberta. CES conference organizers worked with Dedatseetsaa to develop an agenda for the Symposium that built on the broader conference theme of co-creation but with a specific focus on Indigenous evaluation, and they designed an agenda "to highlight work that is being done by Indigenous governments and communities, 
or by non-Indigenous evaluators in partnership with Indigenous governments and communities, in the Northwest Territories and elsewhere; and to provide an opportunity for evaluators and program staff in all levels of government to network, share approaches and methodologies, and promote best practices" (CES, n.d. b).

A key organizing principle for the conference was that the CES organizers and Dedatseetsaa would work in full partnership and collaboration-that the event would be truly co-created. Therefore, instead of just offering time slots for Indigenous presenters, the conference was split into two separate days. The first day of the two-day Symposium was held in a hotel meeting room, with an agenda similar to most academic conferences, including keynote presentations and a panel discussion with an explicit focus on evaluation. For the second day of the conference, the agenda was developed by Dedats'eetsaa. They decided to set aside traditional Western academic notions of knowledge transmission and instead to privilege Indigenous methods. The focal point for the day's agenda was to highlight Boots on the Ground, a caribou monitoring program that involves participatory action research using traditional Indigenous monitoring methods. The agenda was turned over to the Tlıchọ experts, including Elders, and the sessions were held at a land-based venue outside of Yellowknife, with break-out sessions held in tipis or around campfires. Elders and program staff spoke in their own words about the program, about their research methods, and their findings, often speaking in their own language with the use of simultaneous interpretation. The rhythm and pacing of presentations were markedly different from the first day.

Some 115 people attended the Symposium, with about one third of the participants identifying as evaluators. An indication of the emerging interest in evaluation in the NWT is that half of the participants were from the NWT, and seven NWT Indigenous governing organizations were represented. Strong financial support was provided by the GNWT and several corporate sponsors, and substantial in-kind support was provided by the Tłıchọ Government and non-government partners.

Dr. John B. Zoe, Chair of Dedatseetsaa and the Symposium co-chair, opened the Symposium by noting that evaluation sponsored by public government tends to be deficit-based:

The only evaluation we hear today is when GNWT reports on Indigenous people, for example, "rates of Indigenous language use slightly improved but overall education levels are decreasing." . . . Everything is negative. It doesn't capture our strengths, or use these strengths as the foundation for using evaluation.

Zoe went on to explain that the second day of the Symposium would focus on the Tłı chọ Government's Boots on the Ground program, a caribou monitoring program based on the traditional knowledge of Indigenous Elders and harvesters, and that the approach to evaluation would differ from Western evaluation approaches: "Our report is a story, it's different from what you're used to." He closed by stressing the importance of evaluation for Indigenous self-governments, stating, "We know we need to evaluate what we do and see how we can make it stronger." $\mathrm{He}$ 
also noted the value of having several NWT Indigenous governments present at the Symposium, providing an opportunity for them to share best practices and learn from one another-a critical first step in developing a community of interest for Indigenous evaluation in the NWT.

Other Indigenous speakers also highlighted the role of evaluation in promoting and strengthening Indigenous sovereignty. Dr. Nicole Bowman stressed the importance of grounding evaluation in the shared history of colonization and dispossession of lands. Nan Wehipeihana from New Zealand noted that "[e]valuation is part of the cultural DNA of Indigenous people" and outlined several examples of Maori culturally grounded frameworks that have been applied in New Zealand (Wehipeihana, 2018b). Hillory Tenute closed her presentation with a blunt statement about the need for Indigenous approaches and methods to be privileged: "Co-creation and collaboration are fine, but just for one minute, can we just own the space?" Her statement highlighted the need to distinguish between evaluation approaches that, while making sincere efforts to engage Indigenous collaborators in a respectful way, still remain grounded in Western ways of knowing and methods, and evaluation that is initiated by Indigenous people, grounded in Indigenous values and methods, and undertaken by Indigenous evaluators.

\section{Building Indigenous evaluation capacity}

As the interest in Indigenous evaluation increases, so too does the need to build capacity for evaluation among Indigenous scholars and researchers. Hotiì ts'eeda is a research network in the NWT, funded by the Canadian Institutes of Health Research as one of a national network of SPOR SUPPORT Units under the Strategy for Patient-Oriented Research, with a mandate to support health research and training that is rooted in Dene Naowo, Inuvialuit, and Métis knowledge and to respond to the needs of patients and communities (Hotı̀ ts'eeda, n.d.). It commenced operations in 2016. In an effort to respond to priorities brought forward by Indigenous organizations in the NWT, Hotil ts'eeda has identified the need to promote the development of Indigenous evaluation capacity and methods related to health and well-being in the NWT and has implemented an Indigenous evaluation capacity strategy that will provide opportunities for training, professional development, and mentorship to staff of Indigenous organizations working in health and wellness-related programs.

\section{OPPORTUNITIES FOR INDIGENOUS EVALUATION IN NORTHERN CANADA}

The intention of the NWT Evaluation Symposium was to showcase new approaches to evaluation that provide an opportunity to change the narrative of evaluation as a tool of colonization, as something that is imposed on Indigenous governments and organizations by external agencies and not relevant to their needs and priorities. Terms such as culturally responsive evaluation, Indigenous evaluation, and Indigenous evaluation frameworks have been used by different 
authors to encompass several dimensions of evaluative activity, generally falling into three broad categories:

- culturally responsive evaluation: evaluation conducted by non-Indigenous evaluators that is "intentional and inclusive when selecting and implementing evaluation design and methods based on the culture and contextual needs of the project, context, participants, and stakeholders" (Bowman et al., 2015);

- co-created evaluation: where both Indigenous and Western knowledge are equally respected and utilized as appropriate in designing evaluation approaches (Superu, 2018); and

- Indigenous evaluation: evaluation by Indigenous people, for Indigenous people, as Indigenous people (Wehipeihana, 2018b).

These distinctions provide a useful framework for discussion of the opportunities for the utilization of Indigenous evaluation approaches in Northern Canada. As described above, the NWT governance landscape includes a range of programs and services variously delivered by public governments, non-government organizations, and Indigenous organizations and governments, as well as initiatives that operate under collaborative or co-management agreements. This diversity of governance and funding arrangements will be a permanent feature of governance in the NWT, thus requiring an equally diverse evaluation toolkit. These distinct evaluation approaches and their potential for utilization in the NWT are explored below.

\section{Culturally responsive evaluation}

Several authors have addressed the need for non-Indigenous evaluators working in Indigenous contexts to practise evaluation that is grounded in the cultural context of the community in which the evaluation is taking place, respects Indigenous beliefs and protocols, applies culturally relevant measures that flow from community-defined values, and meaningfully engages Indigenous people in the design and conduct of all stages of the evaluation (Bowman et al., 2015; Chouinard \& Cousins, 2007; LaFrance \& Nichols, 2008). Given the extensive literature, it is reasonable to state that the precepts of culturally responsive evaluation (CRE) have become widely acknowledged and generally accepted by the evaluation profession in North America.

Both Bowman et al. (2015) and Wehipeihana (2018b) have stressed the importance of the role that non-Indigenous evaluation allies play in the contemporary context where there are few Indigenous evaluation practitioners trained to participate in evaluation-related activities, in effect considering CRE not only as a valid evaluation approach in its own right but also as a much-needed bridging mechanism to a future where capacity issues will no longer hamper Indigenous evaluation approaches.

Bowman et al. (2015) have also noted the utility of CRE in contexts where there may be a lack of clarity with respect to who has jurisdiction for delivery of 
services in situations where, for example, tribal peoples reside in non-tribal areas. This is particularly relevant in the NWT where there is considerable mobility among regions and where employment opportunities tend to be found in regional centres and in Yellowknife, the capital city, resulting in a large proportion of the residents of self-governing entities living outside the area where their Indigenous government has jurisdiction.

There will be an ongoing need for CRE in NWT as public governments will continue to provide the greatest proportion of programs and services for the foreseeable future, and in order for evaluation in this context to be effective it requires cultural competence and an ability to work effectively in Indigenous and non-Indigenous contexts. The GNWT, in its ongoing role as a public government, will continue to be a major funder and delivery agent for programs and services in the NWT. Given that half of the territory's population is Indigenous, demonstrated competence in CRE methods and approaches should be a requirement embedded in policies, protocols, and practices for any evaluation undertaking that involves programs and services delivered to, on behalf of, or in partnership with Indigenous residents and governments. Compared to many public government institutions, the GNWT has been progressive in its efforts to acknowledge and incorporate Indigenous culture, values, and ways of knowing in its worksee, for example, the Traditional Knowledge Policy (GNWT, 2005), the Culture and Heritage Strategic Framework (GNWT, 2015), and the Respect/Recognition/ Responsibility policy (GNWT, n.d. a). GNWT's evaluation policies and protocols, however, are outdated and contain no explicit mention of CRE or Indigenous evaluation, other than an indication that evaluators must "respect the culture that you will be working in" (GNWT, 2014). While any evaluation undertaking dealing with a GNWT program should be informed by the overarching policy documents noted above, explicit direction and support for evaluators working with Indigenous populations in the NWT should be developed. The Australian government has shown leadership in this area by initiating the development of a whole-of-government evaluation strategy for policies and programs affecting Indigenous Australians (Government of Australia, 2019).

Culturally responsive evaluation approaches are likely to be most effective when applied to situations where jurisdiction remains with the Government of Canada or GNWT but where program beneficiaries include Indigenous residents and communities.

\section{Co-created evaluation}

Co-created evaluation builds on the precepts of CRE but is premised on the assumption of true partnership between Indigenous and non-Indigenous participants at every level. Co-created evaluation requires more than recognition and respect for Indigenous epistemology and methods. As the theme for the CES 2018 Conference, co-creation was described as follows: "Co-creation challenges traditional power relationships. It requires an evaluator to be a methodological expert, facilitator, critic, ally and strategic thinker who can move evaluation to enable 
change while sharing jurisdiction. It speaks to developing true partnerships, to building evaluations from the ground up and to acknowledging that other methods and perspectives have equal weight to our own" (CES, n.d. a).

Kate McKegg has explored the power relationships inherent in research and evaluation. She asserts the need for this issue to be addressed explicitly in order to truly co-create an evaluation approach and has written about the need to shift the balance of power, stating that "(white) evaluators and others with power to resource need to invest in and support the development of evaluators from other cultures to lead and to determine whose values hold sway" (Wehipeihana, Davidson, McKegg, \& Shanker, 2010, p. 189). For co-created evaluation to be genuine, Indigenous and non-Indigenous epistemologies must be equally privileged; as Wehipeihana notes, "there is no substitute for cultural capital that comes from being within the culture; some things can't be learnt or explored simply with a 'culturally responsive' lens" (Wehipeihana et al., 2010, p. 188).

As challenging as this is, Canadian evaluators are going to have to come to grips with the growing need for co-created evaluation in situations where jurisdiction or program delivery responsibility is shared between Indigenous and non-Indigenous governments, or even among Indigenous government organizations. Bowman et al. (2015, p. 341) note that the evaluation community will benefit from a multijurisdictional framework in situations where governments are linked into "an interconnected system that helps agencies form policy task forces and working groups; develop information and resource sharing practices; form political alliances; create memos of understanding and legal ordinances or structures; and carry out research and evaluation studies to properly document evidence-based programs and practices carried out in municipal, state, federal and Tribal contexts."

The NWT is well positioned to become a leader in the development of protocols and methods for, and utilization of, co-created evaluation approaches. As more Indigenous governments contemplate administrative service arrangements with the GNWT and co-management arrangements become more established, there will be an increasing need for robust evaluation approaches that reflect the spirit of shared jurisdiction, that equally privilege Indigenous and Western knowledges and methods, and that produce results and recommendations that are perceived as credible and relevant by all knowledge users.

Canadian evaluators and social scientists frequently cite the concept of "twoeyed seeing" to describe an approach where Indigenous and non-Indigenous knowledges are integrated through a process of learning to see from one eye with the strengths of Indigenous ways of knowing, and from the other eye with the strengths of Western knowledge, and weaving these together (National Collaborating Centre on Aboriginal Health, 2013). The Tł̣chǫ Government promotes the philosophy of "strong like two people," which recognizes the value of both Western and Indigenous knowledge systems and the need to be able to operate effectively in both contexts (Tłıchǫ Government, n.d.). What these philosophies 
have in common is that they do not privilege one form of knowledge over another but acknowledge merit in multiple perspectives (Waapalaneexkweew, 2018). This is an admirable goal but can be difficult to achieve in reality, especially in a context where power and privilege have generally accrued to Western epistemologies and methods. Co-creation is not about Indigenizing Western evaluation but can be effective only when evaluation frameworks and methods are designed in true partnership, drawing on knowledge, values, and research methods from Indigenous and Western spheres as needed to arrive at the most appropriate and effective evaluation approach for the specific context of the evaluation. Further, as Gaudry (2015, p. 260) notes, "Non-Indigenous researchers hoping to carry out research with Indigenous people or in Indigenous communities must be prepared to navigate settler-Indigenous and colonizer-colonized relationship."

Various authors have proposed models for designing co-created evaluation approaches; for example, Martinez et al. (2018, p. 35) describe a model for cocreating collaborative evaluation for tribal child welfare programs in the United States, citing its potential to "build a new narrative for program planning and evaluation."

The experience of the NWT Evaluation Symposium highlights some of the challenges the profession will face in crafting approaches to co-creation. In responding to the evaluation survey, the majority of the participants who responded (33\% response rate) were positive about having the opportunity to learn in an Indigenous context from Indigenous experts and to hear the unique perspectives of Indigenous researchers. However, there were also comments that revealed dissatisfaction or discomfort with the Day 2 sessions. Some respondents indicated that they were not comfortable with the unstructured approach of the on-the-land sessions, that they found the day to be poorly organized, and that listening through interpreters was challenging. Some respondents expressed a desire for more focused and systematic presentations. It may be that, pushed out of their comfort zones, some evaluators experienced for the first time how many Indigenous people have reacted to the experience of participating in academic conferences, highlighting what McKegg has described as the need for non-Indigenous evaluators to "understand ourselves as 'cultural beings' and to acknowledge that our cultural worldview is not 'best' or 'better', it is different" (Wehipeihana et al., 2010, p. 189).

Co-created evaluation approaches will have particular relevance in situations where public and Indigenous government share responsibility for program delivery and where Indigenous governments and other organizations rely on external funding sources to support critical programs, as is currently the case with some land-based programs.

\section{Indigenous evaluation}

The ultimate goal for Indigenous governments is to utilize evaluation that is grounded in Indigenous ways of knowing and responds to the priorities and values of Indigenous communities, and to use evaluation not only for internal 
accountability but also for ongoing program improvement. This goes far beyond training Indigenous people in Western evaluation methods:

Indigenous evaluation is not just a matter of accommodating or adapting majority perspectives to American Indian contexts. Rather, it requires a total reconceptualization and rethinking. It involves a fundamental shift in worldview. Indigenous methodology challenges us to rethink both epistemology and method. Although methods of indigenous evaluation share common ground with qualitative methods, the two are not synonymous. (LaFrance, Nichols, \& Kirkhart, 2012, p. 61)

As Indigenous governments in the NWT advance the process of negotiation and implementation of self-government agreements, there will be an increased role for Indigenous evaluation in supporting program and service delivery by Indigenous governments, for Indigenous residents. Non-government Indigenous organizations are also increasingly seeking to rely on Indigenous evaluation approaches and methods to support their program delivery and improvement, as evidenced by attendance at the NWT Evaluation Symposium.

Indigenous evaluators are breaking down the historical barriers of distrust by grounding evaluation approaches in Indigenous values and cosmologies, using methods that are familiar and appropriate in local Indigenous contexts and changing the language of evaluation to be more responsive to Indigenous ways of knowing.

Is there a role for non-Indigenous evaluators to participate in, or contribute to, Indigenous evaluation? Informal and undocumented feedback received by the organizers after the NWT Evaluation Symposium indicated that some nonIndigenous evaluators were made uncomfortable by the emphasis on Indigenous evaluation as an enterprise that must be Indigenous-led, questioning what the role of non-Indigenous evaluators and Western approaches might be in a future NWT context. In her keynote address to the CES 2018 Conference, Nan Wehipeihana noted that while the goal of Indigenous evaluation is to have evaluation that is done by Indigenous peoples, for Indigenous peoples, as Indigenous peoples, the current reality is that there is a shortage of Indigenous practitioners trained to play this role, so there is a role for non-Indigenous evaluators to participate in both co-created and Indigenous evaluation. However, she stressed, this is "by invitation with no automatic or presumed right of leadership" (Wehipeihana, 2018a). As Indigenous governments expand their role in taking ownership of evaluation, non-Indigenous evaluators have to be willing to step aside and recognize that while being an ally sometimes means collaborating and supporting, sometimes it just means getting out of the way.

The preceding sections focus on how the development of Indigenous evaluation in the NWT may contribute to the broader public discourse on this topic. But there is another, critically important, aspect to the role that a better understanding of Indigenous evaluation approaches can play in today's world. Michael Quinn Patton and others are promoting the concept of Blue Marble Evaluationevaluation that is "aimed at transforming systems towards a more sustainable 
world," breaking down silos and creating linkages to make global systems more sustainable (Patton, n.d.). Andy Rowe (2019, p. 29) has echoed this theme in his promotion of the need for sustainability-ready evolution, that is, "evaluation that recognises that human and natural systems are coupled, and that current evaluation portfolios are now and will increasingly be affected by natural system forces including climate." Rowe and others have criticized current evaluation approaches as falling short of the scope needed to be sustainability-ready because evaluation generally treats human and natural systems as unconnected. In a keynote panel presentation on "Evaluation for the Anthropocene" at the CES 2018 Conference, panel members noted how Indigenous worldviews, which are rooted in place and perceive mankind as part of a broader ecosystem, provide the means to bridge this gap in evaluation approaches. Sean Curry argued that environmental science doesn't say "no" until hard science proves a negative impact, but that when an issue is viewed through an Indigenous lens, there will be a different, more nuanced, outcome. Jane Davidson proposed that a core value of sustainability-ready evaluation should be that evaluation must be responsive to the needs of the community but without compromising the ability of future generations to enjoy the use of the land and resources-a value that is congruent with Indigenous understanding of responsibility for stewardship of lands and resources (CES, 2018).

These perspectives are mirrored in the work of Indigenous evaluators. Wehipeihana (2018b) states, "Our conservation and guardianship practices are a form of evaluation for the protection and sustainability of mother earth and ourselves." Zoe, a recognized expert in Tłl chǫ cosmology, continually returns to this theme in his work. In explaining the importance of the evaluation approach reflected in the Boots on the Ground project to participants at the NWT Evaluation Symposium, he noted that the program is founded on the principle of having on-the-land experiences informing research: "All the information, all the knowledge that we need is still on the land." Boots on the Ground is, in fact, a sophisticated, mixed-methods evaluation of the interplay of human and natural systems and their impact on one another; the project's purpose, as described by Zoe, is to determine "what impact is [the decline of the caribou herd] having on us, and how do we make it public to our people." Stressing the essential linking between human and natural systems, Zoe asserted the need to make policymakers understand that "the goal is not to get people off the land, the goal is to get people on the land with the caribou. We have co-existed since time immemorial. We're partners-if one of us is missing, the other is going to wander away."

Rowe (2019, p. 43) asserts that in order for evaluation to be relevant in a twentyfirst-century context, it must "incorporate different worldviews that regard human and natural systems as coupled and each important" and concludes that "Indigenous evaluation approaches that incorporate Indigenous worldviews could prove to be the polar star for sustainability-ready evaluation." The development of Indigenous evaluation approaches in the NWT and elsewhere has a role to play in addressing issues of critical importance to twenty-first-century society, beyond its immediate application to the needs and priorities of Indigenous governments. 


\section{CONCLUSION}

As Bowman et al. (2015) have noted, building Indigenous evaluation capacity and capability will require a substantial investment. They describe the scope of the work to be done with respect to training, developing common policies and methods, and data sharing protocols as "staggering." But their conclusion about why this investment is worthwhile rings true for Canada as well as the United States: "without evaluation capacity building within, across and outside of Indian Country, the pattern of long-term educational, economic, health, and other disparities that Indian people have endured will likely continue" (Bowman et al., 2015, p. 352).

The multi-dimensional governance landscape in the NWT provides opportunities for advancing the understanding and utilization of culturally responsive evaluation, co-created evaluation, and Indigenous evaluation approaches. All three have relevance, but consideration will be needed to determine which approach is the most appropriate in any given situation.

There is an opportunity for the GNWT to update and enhance its evaluation policies and guidelines to formalize the use of CRE as an appropriate evaluation approach for work in NWT communities, and to ensure that Indigenous ways of knowing and research methods are given equal or greater weight than nonIndigenous approaches and methods. The requirement for a CRE approach when appropriate can be built into the contracting process for government-sponsored evaluation projects.

In the NWT, Indigenous governments are leading the way in developing research and evaluation approaches rooted in Indigenous knowledge and values. NWT stakeholders with an interest in evaluation have fertile ground to develop and test protocols for co-created evaluation, and to build on learnings and share best practices with one another and the rest of Canada-both through existing forums such as CES meetings and publications, and through new communities of interest that may be formed to promote Indigenous evaluation in the north and across Canada.

There is a need not only in the NWT, but throughout Canada, for learning and research institutions to make an intentional investment in the nascent field of Indigenous evaluation, supporting research, publications, and training wherever possible. Targeted opportunities must be made available for Indigenous researchers and practitioners who want to advance their own skills in this area.

CES can play a role by continuing to advance the public discourse, using its privileged position as the curator of evaluator credentialing in Canada to advocate for the credibility and legitimacy of Indigenous evaluation approaches.

\section{REFERENCES}

Bowman, N., Francis, C. D., \& Tyndall, M. (2015). Culturally responsive Indigenous evaluation: A practical approach for evaluating Indigenous projects in tribal reservation contexts. In S. Hood, R. Hopson, \& H. Frierson (Eds.), Continuing the journey to reposition culture and cultural context in evaluation theory and practice (pp. 335-359). Charlotte, NC: Information Age Publishing. 
Burgess, C. P., Johnston, F. H., Berry, H. L., McDonnell, J., Yibarbuk, B., Gunabarra, C., Mileran, A., \& Bailie, R. S. (2009). Healthy country, healthy people: The relationship between Indigenous health status and "caring for country." Medical Journal of Australia, 190(10), 567-572. https://doi.org/10.5694/j.1326-5377.2009.tb02566.x

Burgess, C. P., Mileran, A., \& Bailies, R. (2008). Beyond the mainstream: Health gains in remote Aboriginal communities. Australian Family Physician, 37(12), 986-988. Medline: 19142270

Canadian Evaluation Society. (2018, May 29). Evaluation for the Anthropocene [Video]. Retrieved from https://www.youtube.com/watch?v=pof8x4ONkF0

Canadian Evaluation Society. (n.d. a). Co-Creation 2018: Theme. Retrieved from http:// c2018.evaluationcanada.ca/program/conference-theme/

Canadian Evaluation Society. (n.d. b). NWT evaluation symposium May 31-June 1, 2018: Final report. Retrieved from http://www.nwtevaluation2018.com/uploads/ 1/1/5/2/115215549/final_compressed_ces_2018_nwt_evaluation_symposium_final_ report_march_7.19_with_photos-merged-compressed.pdf

CBC North. (2017, March 17). How should northern on-the-land programs be evaluated? Retrieved from https://www.cbc.ca/news/canada/north/nwt-on-the-land-summit-1. 4028973

Chouinard, J. A., \& Cousins, J. B. (2007). Culturally competent evaluation for aboriginal communities: A review of the empirical literature. Journal of MultiDisciplinary Evaluation, 4(8), 40-57. Retrieved from http://journals.sfu.ca/jmde/index.php/jmde_1/ article/view/30

DeLancey, D., Radu, I., Enosse, L., \& Ritchie, S. (2018). Measuring connection: Evaluating land-based programs. Northern Public Affairs, 6(1), 39-44.

Délînê Got'ine Government. (2013). Délînê final self-government agreement. Retrieved from https://www.deline.ca/wp-content/uploads/2016/10/Deline-Final-Self-GovernmentAgreement.pdf

Gaudry, A. (2015). Researching the resurgence: Insurgent research and community-engaged methodologies in $21^{\text {st }}$-century academic inquiry. In S. Strega \& L. Brown (Eds.), Research as resistance: Revisiting critical, Indigenous, and anti-oppressive approaches (pp. 243-263). Toronto, ON: Canadian Scholars' Press.

Government of Australia. (2019, June). Indigenous evaluation strategy: Productivity commission issues paper. Retrieved from https://www.pc.gov.au/inquiries/current/ indigenous-evaluation/issues/indigenous-evaluation-issues.pdf

Government of the Northwest Territories. (2001). Social agenda: A draft for people of the NWT. Retrieved from http://pubs.aina.ucalgary.ca/health/53330E.pdf

Government of the Northwest Territories. (2005, March). Traditional knowledge policy. Retrieved from https://www.eia.gov.nt.ca/sites/eia/files/content/53.03-traditionalknowledge.pdf

Government of the Northwest Territories. (2014, November). Program review office handbook-Appendix A: Program design and planning manual; Appendix B: Program monitoring and evaluation manual. Retrieved from https://www.fin.gov.nt.ca/ en/resources?search_api_views_fulltext=Program+Review+Office+Handbook\&so rt_by=field_resource_publication_date\&sort_order=DESC 
Government of the Northwest Territories. (2015, October). Strong cultures, strong territory: GNWT culture and heritage strategic framework 2015-2015. Retrieved from https://www.ece.gov.nt.ca/sites/ece/files/resources/culture_and_heritage_framework_ 2015-2025.pdf

Government of the Northwest Territories. (n.d. a). Respect recognition responsibility: The government of the Northwest territories' approach to engaging with Aboriginal governments. Retrieved from https://www.eia.gov.nt.ca/sites/eia/files/rrr_english_brochure.pdf

Government of the Northwest Territories. (n.d. b). Indigenous governments of the NWT. Retrieved from https://www.eia.gov.nt.ca/sites/eia/files/04_gnwt_rrr_brochure_2012public.pdf

Gregory, R., Easterling, D., Kaechele, N., \& Trousdale, W. (2016). Values-based measures of impacts to Indigenous health. Risk Analysis, 36(8), 1581-1588. https://doi. org/10.1111/risa.12533

Hotı̀ ts'eeda. Northwest Territories SPOR SUPPORT Unit. (n.d.). [Home page.] Retrieved from https://nwtspor.ca/

Inuit Tapiriit Kanatami. (2019). Request for Proposals (RFP): Supporting monitoring, evaluation learning at ITK. Retrieved from https://myitk.bamboohr.com/jobs/view.php?id=48

Kawakami, A. J., Aton, K., Cram, F., Lai, M. K., \& Porima, L. (2007). Improving the practice of evaluation through Indigenous values and methods: Decolonizing evaluation practice-returning the gaze from Hawai'i and Aotearoa. Hülili: Multidisciplinary Research on Hawaiian Well-Being, 4(1), 319-348. Retrieved from http://citeseerx.ist. psu.edu/viewdoc/download?doi=10.1.1.553.692\&rep=rep1\&type $=$ pdf

Kovach, M. (2009). Indigenous methodologies: Characteristics, conversations, and contexts. Toronto, ON: University of Toronto Press.

LaFrance, J., Nichols, R., \& Kirkhart, K. E. (2012). Culture writes the script: On the centrality of context in indigenous evaluation. In D. J. Rog, J. L. Fitzpatrick, \& R. F. Conner (Eds.), Context: A framework for its influence on evaluation practice. New Directions for Evaluation, 2012(135), 59-74. https://doi.org/10.1002/ev.20027

LaFrance, N., \& Nichols, R. (2008). Reframing evaluation: Defining an indigenous evaluation framework. Canadian Journal of Program Evaluation, 23(2), 13-31.

Legislative Assembly of NWT. (2019, October 25). Caucus identifies priorities for the 19th Legislative Assembly. Retrieved from: https://www.assembly.gov.nt.ca/documentsproceedings/news-releases

Martinez, A., Running Wolf, P., BigFoot, D. S., Randall, C., \& Villegas, M. (2018). The process of becoming: A roadmap to evaluation in Indian country. New Directions for Evaluation, 2018(159), 33-45. https://doi.org/10.1002/ev.20333

National Collaborating Centre for Aboriginal Health. (2013). Indigenous approaches to program evaluation. Retrieved from https://www.nccih.ca/495/Indigenous_Approaches_ to_Program_Evaluation.nccih?id=125

Patton, M. Q. (n.d.). Blue marble evaluation. Retrieved from https://bluemarbleeval.org/about

Redvers, J. M. (2016). Land-based practice for Indigenous health and wellness in Yukon, Nunavut, and the Northwest Territories (Master's thesis). University of Calgary, Calgary, AB. http://doi.org/10.11575/PRISM/26717 
Rowe, A. (2019). Sustainability-ready evaluation: A call to action. New Directions in Evaluation, 2019(162), 29-48. https://doi.org/10.1002/ev.20365

Statistics Canada. (2017, November 29). Northwest Territories [Territory] and Canada [Country] (table). Census Profile. 2016 Census. Statistics Canada Catalogue no. 98316-X2016001. Ottawa, ON: Author. Retrieved from https://www12.statcan.gc.ca/ census-recensement/2016/dp-pd/prof/index.cfm?Lang=E

Superu (Social Policy Evaluation and Research Unit). (2018). Bridging cultural perspectives. Wellington, New Zealand: Government of New Zealand.

Tides Canada, Sahtu Renewable Resources Board, NWT Recreation \& Parks Association, \& Government of Northwest Territories. (2018, November 1-2). On the land evaluation workshop report of the meeting. Retrieved from http://www.nwtontheland.ca/uploads/8/6/5/1/86514372/final_otl_evaluation_meeting_nov_1-2_2018_ report.pdf

Tłıchǫ Government. (2003). Tłıchǫ Intergovernmental Services Agreement. Retrieved from https://www.tlicho.ca/content/tlicho-intergovernmental-services-agreement

Tłıchọ Government. (n.d.). Research and Training Institute Fact Sheet. Retrieved from https://research.tlicho.ca/sites/default/files/research_training_institute_fact_sheets. pdf

Waapalaneexkweew (N. R. Bowman-Farrell). (2018, December). Looking backward but moving forward: Honoring the sacred and asserting the sovereign in indigenous evaluation. American Journal of Evaluation, 39(4), 543-568. https://doi. org/10.1177/1098214018790412

Wehipeihana, N. (2018a, May 27). Reconciliation and culturally responsive evaluation: Rhetoric or reality. Keynote address to CES annual conference. Retrieved from https:// c2018.evaluationcanada.ca/wp-content/uploads/sites/11/2018/08/ReconciliationCulturallyResponsiveEvaluation_slides.pdf

Wehipeihana, N. (2018b, June 1). Affirming and privileging Indigenous knowledge in evaluation. Presentation to NWT Evaluation Symposium. Retrieved from http://www. nwtevaluation2018.com/presentations.html

Wehipeihana, N., Davidson, E. J., McKegg, K., \& Shanker, V. (2010, December). What does it take to do evaluation in communities and cultural contexts other than our own? Journal of MultiDisciplinary Evaluation, 6(13). Retrieved from http://journals.sfu.ca/ jmde/index.php/jmde_1/article/view/265/256

Wildcat, M., McDonald, M., Irlbacher-Fox, S., \& Coulthard, G. (2014). Learning from the land: Indigenous land-based pedagogy and decolonization. Decolonization: Indigeneity, Education and Society, 3(3), I-XV.

Williams, M. (2018). Ngaa-bi-nya Aboriginal and Torres Strait Islander program evaluation framework. Evaluation Journal of Australasia, 18(1), 6-20. https://doi.org/10.1177\% 2F1035719X18760141

\section{AUTHOR INFORMATION}

Debbie DeLancey has worked in the Northwest Territories with Indigenous organizations and the Government of the Northwest Territories for more than 40 years. She is currently 
an Organizational Development Advisor with Hotı̀ ts'eeda, the NWT SPOR SUPPORT Unit. Debbie has an MAE in evaluation from the University of Melbourne and holds the Credentialled Evaluator designation with the Canadian Evaluation Society. Her interests include health systems policy, land-based programming and advancing the utilization of Indigenous evaluation approaches. 